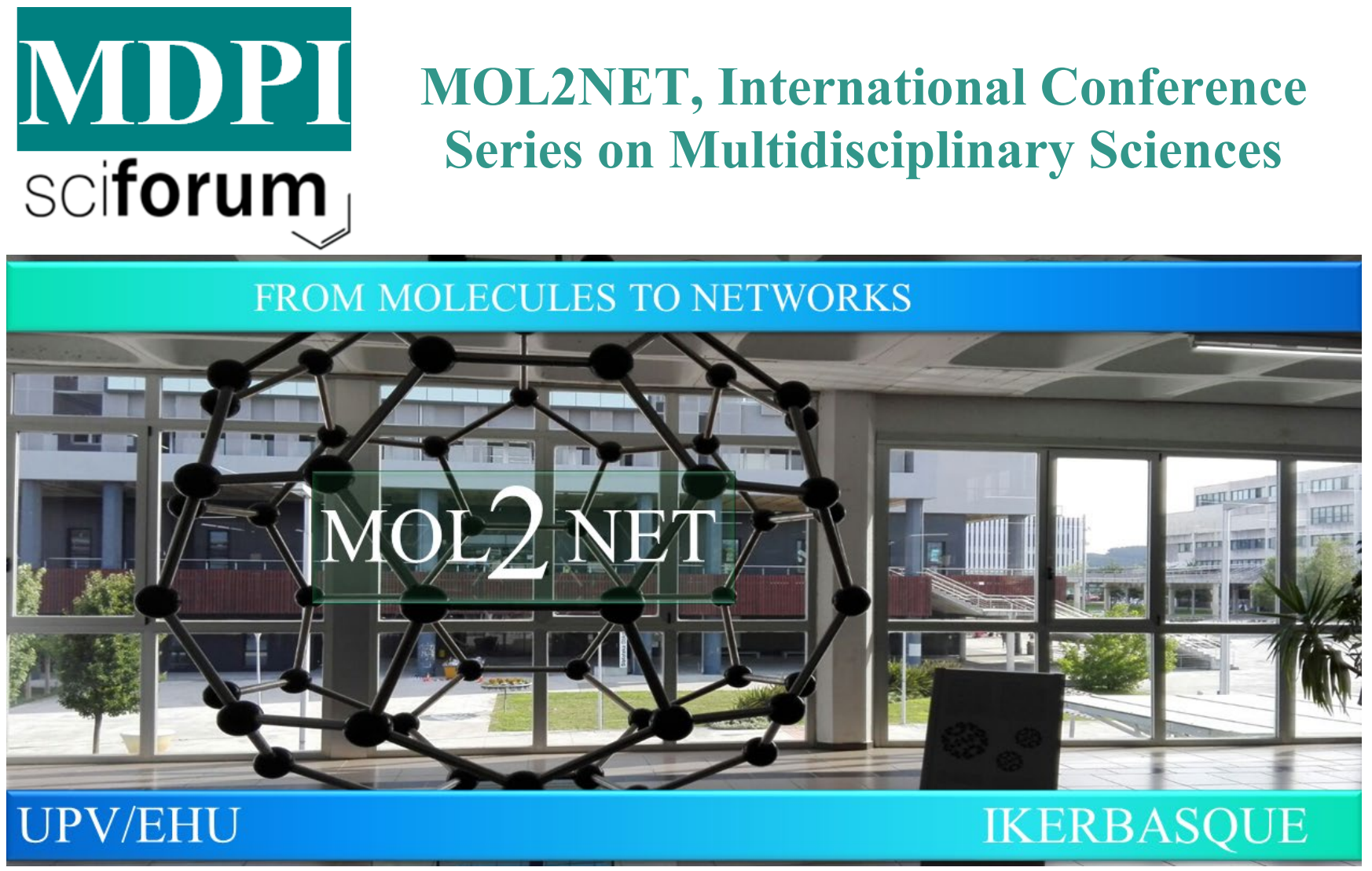

\title{
Profile of the expression of genes and the proteins encoded by them related to the phenomenon of loss of an adequate response to treatment in endometrial cancer
}

Piotr Januszyk ${ }^{a}$, Beniamin Oskar Grabarek ${ }^{b}$, Dariusz Boroń ${ }^{b}$

${ }^{a}$ Department of Biochemistry, Faculty of Medicine in Zabrze, University of Technology in Katowice, Poland

${ }^{b}$ Department of Histology, Cytophysiology and Embryology, Faculty of Medicine in Zabrze, University of Technology in Katowice, Poland

Graphical Abstract

Abstract.

The occurrence of the phenomenon, where loss of an adequate response to anti-cancer treatment is observed, or drug resistance, is connected with, among other things: the occurrence of new DNA mutations; metabolic changes in cancer cells; drug inactivation; inhibition of cancer cell apoptosis; the 


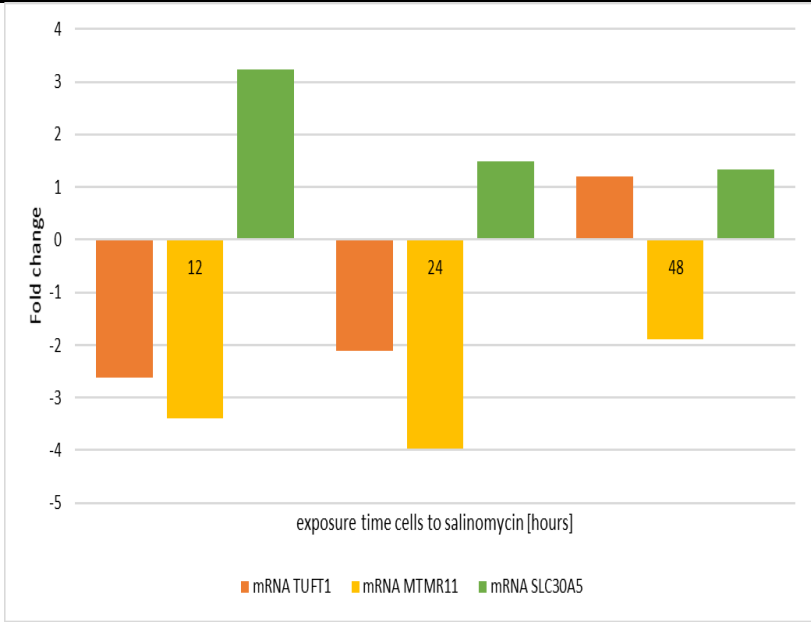

Figure 1. Expression of TUFT1, MTMR11 and SLC30A5 depending on the exposure time of the Ishikawa cell line to salinomycin. epithelial-mesenchymal transition (EMT); heterogeneity of the cells constituting the tumor mass; the influence of epigenetic factors; as well as any combination of the listed factors.

The main aim of this study was to determine the expression profile of $m R N A$ related with the drug resistance phenomenon in Ishikawa line endometrial cancer cells treated with salinomycin compared to the control culture. Ishikawa line endometrial cancer cells were exposed to salinomycin at a concentration of $1 \mu M$ over a period of 12,24 and 48 hours, compared to a control culture, which was formed of cells untreated by the drug. Assessing the microarray expression profile of genes related to drug resistance, it was observed that the number of $m R N A$ differentiating the culture incubated with the drug from the control, depending on the exposition time of the cells to salinomycin was the following: $H_{-} 12$ vs $C-9$ $m R N A$; H_24 vs $C-7 \mathrm{mRNA}$; H_48 vs $\mathrm{C}-1$ $m R N A$. The largest changes in gene expression were determined for: TUFT1; ABCB1; MTMR 11; SLC30A5.

Based on the conducted research as part of this study, it was confirmed that salinomycin added to the Ishikawa line endometrial cancer cell culture indices changes in the mRNA transcriptome related to the drug resistance phenomenon and caspase pathway. Furthermore, we observed that salinomycin induces apoptosis in endometrial cancer cells, mainly through the mitochondrial pathway.

\section{Introduction (optional)}

The occurrence of the phenomenon, where loss of an adequate response to anti-cancer treatment is observed, or drug resistance, is connected with, among other things: the occurrence of new DNA mutations; metabolic changes in cancer cells; drug inactivation; inhibition of cancer cell apoptosis; the epithelial-mesenchymal transition (EMT); heterogeneity of the cells constituting the tumor mass; the influence of epigenetic factors; as well as any combination of the listed factors. 
The main aim of this study was to determine the expression profile of mRNA and miRNA related with the drug resistance phenomenon in Ishikawa line endometrial cancer cells treated with salinomycin compared to the control culture.

\section{Materials and Methods (optional)}

Ishikawa line endometrial cancer cells were exposed to salinomycin at a concentration of $1 \mu \mathrm{M}$ over a period of 12,24 and 48 hours, compared to a control culture, which was formed of cells untreated by the drug.

\section{Results and Discussion (optional)}

Assessing the microarray expression profile of genes related to drug resistance, it was observed that the number of $m R N A$ differentiating the culture incubated with the drug from the control, depending on the exposition time of the cells to salinomycin was the following: $H_{-} 12$ vs $C-9$ mRNA; $H \_24$ vs $C$ $7 \mathrm{mRNA} ; H_{4} 48$ vs $\mathrm{C}-1 \mathrm{mRNA}$. The largest changes in gene expression were determined for: TUFT1; ABCB1; MTMR11; SLC30A5.

\section{Conclusions (optional)}

Based on the conducted research as part of this study, it was confirmed that salinomycin added to the Ishikawa line endometrial cancer cell culture indices changes in the mRNA and miRNA transcriptome related to the drug resistance phenomenon and caspase pathway. Furthermore, we observed that salinomycin induces apoptosis in endometrial cancer cells, mainly through the mitochondrial pathway.

\section{References (mandatory)}

1. Raglan O, Kalliala I, Markozannes G, Cividini S, Gunter MJ, Nautiyal J, Gabra H, Paraskevaidis E, Martin-Hirsch P, Tsilidis KK, Kyrgiou M. Risk factors for endometrial cancer: an umbrella review of the literature. IJC 2019; 145(7): 1719-1730.

2. Webb BJ, Sorensen J, Mecham I, Buckel W, Ooi L, Jephson A, Dean NC. Antibiotic Use and Outcomes After Implementation of the Drug Resistance in Pneumonia Score in ED Patients With Community-Onset Pneumonia. Chest 2019; 156(5): 843-851.

3. Holohan C, Van Schaeybroeck S, Longley DB, Johnston PG. Cancer drug resistance: an evolving paradigm. Nat Rev Cancer 2013; 13(10): 714.

4. Baguley BC. Multiple drug resistance mechanisms in cancer. Mol. Biotechnol 2010; 46(3): 308-316. 